\title{
Target treatment with stereotactic radiation for recurrent gliomas
}

\author{
Ayesha S. Ali ${ }^{1}$, Victor E. Chen ${ }^{1}$, Claire Zurlo ${ }^{2}$, James M. Taylor ${ }^{1}$, Christian Fernandez ${ }^{1}$, Wenyin Shi ${ }^{1}$ \\ ${ }^{1}$ Department of Radiation Oncology, Thomas Jefferson University, Philadelphia, PA, USA; ${ }^{2}$ Sidney Kimmel Medical College, Thomas Jefferson \\ University, Philadelphia, PA, USA \\ Contributions: (I) Conception and design: W Shi, AS Ali; (II) Administrative support: None; (III) Provision of study materials or patients: None; (IV) \\ Collection and assembly of data: AS Ali, C Zurlo, VE Chen; (V) Data analysis and interpretation: AS Ali, VE Chen; (VI) Manuscript writing: All \\ authors; (VII) Final approval of manuscript: All authors. \\ Correspondence to: Wenyin Shi, MD, PhD. Department of Radiation Oncology, Thomas Jefferson University, Philadelphia, PA, USA. \\ Email: Wenyin.Shi@Jefferson.edu.
}

\begin{abstract}
High grade gliomas (HGG) have a propensity to recur locally and have poor outcomes. As such, safe and effective treatment is paramount. Target treatment with stereotactic radiation allows safe re-irradiation through minimizing normal brain tissue radiation due to its high precision. In this review, we evaluated the clinical experiences using SRS and FSRT for re-irradiation in HGG. We report the radiobiological advantages and disadvantages of both modalities as well as the safety and efficacy published in current literature.
\end{abstract}

Keywords: Stereotactic radiation; glioma; radiotherapy; re-irradiation

Submitted Feb 14, 2020. Accepted for publication Mar 04, 2020.

doi: $10.21037 /$ cco.2020.03.05

View this article at: http://dx.doi.org/10.21037/cco.2020.03.05

\section{Introduction}

CNS malignancies account for an estimated $1.3 \%$ of new cancer cases annually and Glioblastoma Multiforme (GBM) is the most common (1). GBM accounts for $15.4 \%$ of all primary brain tumors and $45.6 \%$ of primary malignant brain tumors (2). Anaplastic Astrocytomas, another high grade glioma (HGG) accounts for $6.1 \%$ of all gliomas (3).

Standard of care for HGG entails maximal safe surgical resection followed by adjuvant radiotherapy (RT) and chemotherapy. Unfortunately, many patients recur within 5 to 8 months of definitive treatment (4). Historically, median survival after progression is 6 months (5). While the use of radiotherapy in the primary setting for HGG has been well established, the treatment paradigm in the recurrent setting is less elucidated and varies by institution (4-13). Salvage therapies used alone or in combination include surgery, reirradiation, systemic treatment, tumor treatment fields (TTF) or palliation. Studies have shown a survival benefit with salvage treatment versus palliation (13). Currently, there remains a paucity of data and a lack of general consensus regarding the optimal management strategy for recurrent HGG.
Since the advent of stereotactic radiosurgery (SRS) and fractionated stereotactic radiotherapy (FSRT), more precise and focused targeting is now available and may be preferable in the re-irradiation/salvage setting (14). Various doses and fractionation schedules have been utilized, largely guided by location and volume of recurrence, with various levels of success. In general, SRS has been used for low volume disease while FSRT has been reserved for large volume recurrence (e.g., $>4 \mathrm{~cm}$ ), and allows safe delivery by taking advantage of the radiobiological benefits of fractionation $(15,16)$. Given the poor prognosis of this patient group, efficacy must be balanced by the potential impact on patient quality of life. Herein, we review the various salvage RT series and their respective outcomes.

\section{Radiobiology and physics of SRS and FSRT}

There are key physics, radiobiologic, and dosimetric concepts to recall when evaluating SRS and FSRT regimens for recurrent HGG. From a physics perspective, the basic principles underlying conventionally delivered radiation therapy also guide the clinical use of SRS and 
FSRT. However, SRS and FSRT require a much higher level of accuracy given the modality delivers very high radiation doses over a single or few fractions. Millimeterlevel precision is required in patient positioning with high reproducibility, which can be achieved either with a frame, or as is more common today, with a frameless, mask-based system (17). Target definition accuracy as well as precise image guidance is also critical with the small margins used in SRS and FSRT treatments. Radiobiologically, the literature suggests that high-dose, single fraction treatment primarily acts on tumor-supporting endothelial cells for its tumoricidal effects; in other words, the radiation response can be seen not only in the tumor cells themselves but also in the vasculature (18). The small margins required for SRS and FSRT limit collateral damage to normal tissues.

Kirkpatrick et al. noted that the immunostimulatory effects of SRS and FSRT are important to consider, especially with the growing role of immunotherapy in cancer treatment (19). They argue that although vascular damage may limit the ability of antigens to stimulate the immune system, a hypofractionated regimen such as FSRT, may leave antigen transport mostly intact and result in a stronger immune response than SRS. This is an emerging field of study which has the potential to shift the landscape of radiation techniques in the coming years.

\section{SRS}

In a recent systematic review of SRS in HGG the authors report a median overall survival (OS) of 20 months and progression free survival (PFS) of 5.42 months. In this study, the pooled rate of radiation necrosis $(\mathrm{RN})$ was $5.9 \%$ but ranged from $0-44 \%$ (20). Another review deems SRS a safe and effective minimally invasive treatment for recurrent HGG. They report OS of 13-26 months after recurrence (21).

\section{Dose}

Several prospective trials and retrospective studies have explored dose and fractionation schedules for SRS in recurrent gliomas (Table 1). Doses ranged from 9 to 25 Gy. In some cases, up to 9 lesions were treated with SRS. Others limited SRS to small lesions which were defined differently depending on the study. Generally, doses were attenuated based on size and location of the lesion. Larger lesions and those in proximity to critical structures were prescribed lower doses.
Koga $e t$ al. published a study detailing the local control benefits of extended-field SRS. They evaluated the impact of adding a margin of 0.5 - to $1.0-\mathrm{cm}$ around the enhancing tumor. This study reported a statistically significant difference in local control between extended-field and conventional SRS. However, OS was not statistically significant between conventional and extended-field SRS groups and rates of $\mathrm{RN}$ were slightly higher in the population ( $\mathrm{n}=9$, 35 lesions) studied (26).

Historically, median survival from progression for GBM has been reported as 6 months whether the patients were treated with RT and TMZ upfront or not (5). Studies included in this review had a median OS from SRS ranging from 7 to 14.4 months with a median of 10.6. However, about half (10) studies included both WHO grade III and grade IV gliomas which may favorably skew the OS.

\section{Safety}

The majority of HGG will recur within $2 \mathrm{~cm}$ of the initial (pre-surgical) tumor bed which makes previous RT pertinent to the safety of re-irradiation $(27,28)$. Normal tissue radiation tolerance is dependent on the volume treated, dose, and sensitivity of tissue being treated. Due to the highly conformal nature of both SRS and FSRT, treatment margins are eliminated and less healthy brain tissue is included in the field. This is especially relevant in the recurrent setting in which the majority of patients have already received RT to the area in question (15).

RTOG 9005 explored maximum tolerated dose of SRS in patients with a history of prior RT in primary brain tumors. Although the trial did not focus on gliomas with previous RT up to $60 \mathrm{~Gy}$, it showed that maximum tolerated doses varied based on tumor diameter and that tumor diameter correlated with risk of grade $\geq 3$ neurotoxicity. Twenty-four Gy, 18 Gy and 15 Gy were defined as the maximum tolerated doses for tumors $\leq 2$, $2-3$ and $3-4 \mathrm{~cm}$ respectively (29). Several phase I dose escalation trials have shown varying risk of radionecrosis when utilizing doses above those in RTOG 9005 (30-32).

$\mathrm{RN}$ is perhaps the most serious late side effect of CNS RT. It occurs in brain tissue that has received a normalized tissue dose (NTD) of >100 Gy. Changes in RT technique at re-treatment have not been correlated with an increased risk of this phenomenon. Low initial dose and long intervals between treatments may lead to less neurotoxicity (33-35). Clinically, RN can imitate tumor recurrence with worsening presenting symptoms, new neurological deficits as well as 


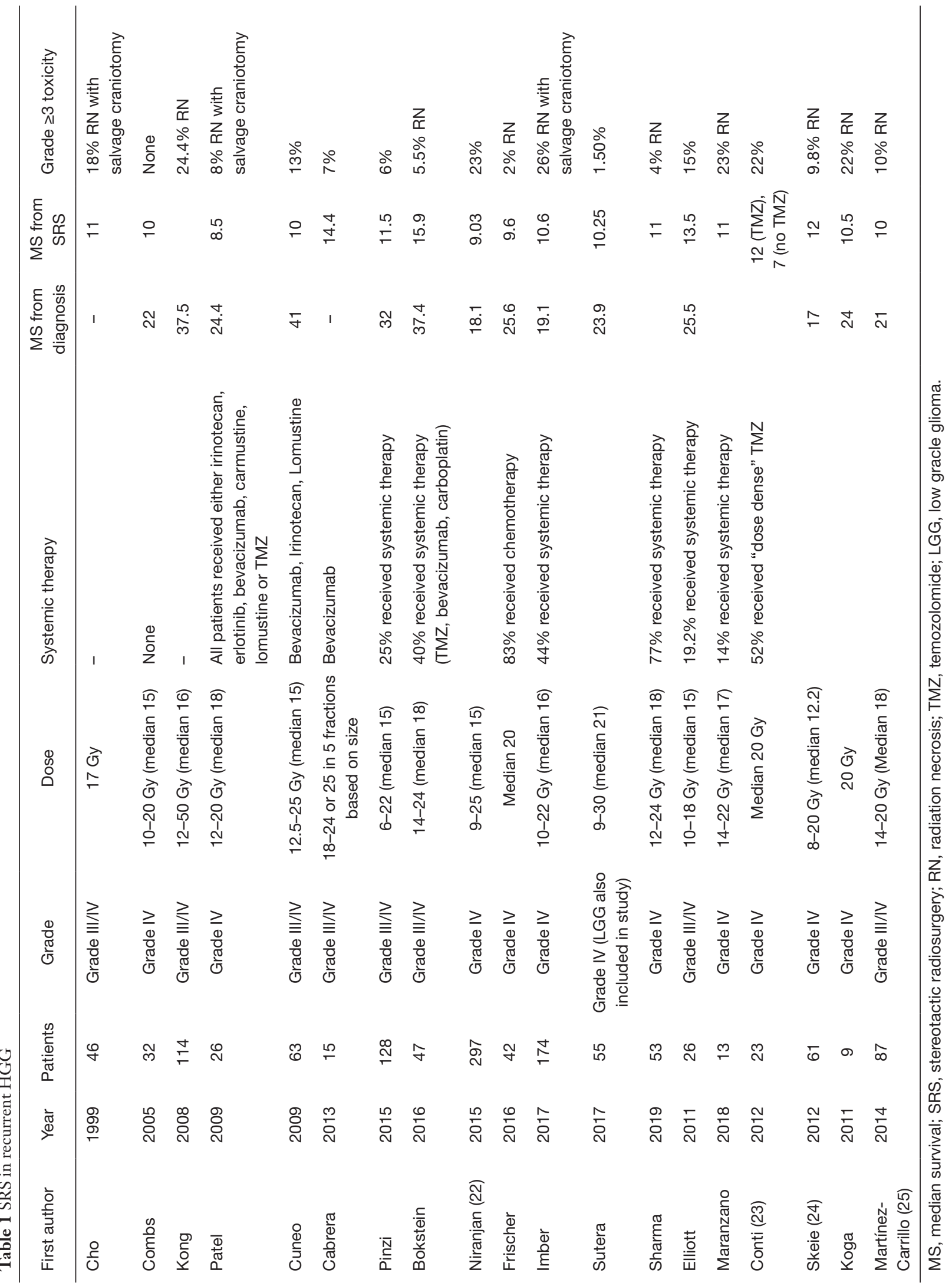


progressing enhancement on imaging. It may ultimately require surgical debulking. Other less invasive treatments may include bevacizumab, corticosteroids or hyperbaric oxygen $(15,36)$.

Some studies showed no grade 3 or higher toxicities while others demonstrated that up to $26 \%$ of patients suffered clinically significant toxicities. A phase I dose escalation trial showed clinically significant toxicities of up to $60 \%$ however there were only 10 patients enlisted in the trial. Only one experienced neurotoxicity and other toxicities were associated with the concurrent systemic therapy (32). In one institutional report, $26 \%$ of 174 GBM patients underwent salvage craniotomy for RN. This report found that larger mean treatment volumes may have predicted for RN. Median volume of lesions treated with SRS in this retrospective study was $7 \mathrm{cc}$ with a maximum of $39 \mathrm{cc}(37)$. Another report found that $23 \%$ of patients experienced $\mathrm{RN}$, however, this only represented 3 patients all three of which had different treatment volumes and different doses (38). Kong et al. reported a $24.4 \% \mathrm{RN}$ rate but further analysis was not commented on. All of these studies used a median of 16 or $17 \mathrm{~Gy}$ (39).

Only one patient in a study by Sutera $e t$ al. experienced $\mathrm{RN}$ (grade 2), but not all patients were strictly treated with SRS. They included up to 8 fractions in their retrospective analysis (40). Another report found only one patient to have $\mathrm{RN}$ out of their 42-patient cohort. Additional diseasespecific data was not offered regarding this patient, but the median dose in this study was 20 Gy (41).

Cabrera et al. included neurocognitive testing and quality of life parameters in their prospective trial of concurrent SRS and bevacizumab. This was assessed through the MiniMental State Examination (MMSE), Trail Making Test Parts A and B (TMT-A/B) and Functional Assessment of Cancer Therapy-Brain (FACT-Br) at baseline, 1 week and 2 months after SRS. Although they reported that neurocognition didn't change during treatment, the physical well-being subscale of the FACT-Br showed significant worsening at the two-month time point compared to baseline or one week evaluations (42).

\section{Systemic therapy}

Varying combinations of systemic therapy and steroids were used in these studies. Doses of these agents also varied. Some patients were pretreated with steroids and others weren't treated with steroids until clinical symptoms worsened. Not all concurrent or adjuvant treatments were detailed in published reports of the included studies.

Bokstein et al. reported a significant survival advantage in GBM patients treated with SRS $v s$. bevacizumab alone (12.6 vs. 7.3 months) (43). However, tumor burden and volume was not matched in this retrospective study and $40 \%$ of the patients in the SRS group received concurrent chemotherapy or biological therapy. Sutera et al. described an association between bevacizumab and inferior outcomes, however, only two patients received bevacizumab in their analysis (40). In contrast, Cuneo et al. described a survival benefit in patients receiving adjuvant bevacizumab after salvage SRS (11.2 vs. 3.9 months). They also reported a PFS benefit in this population (5.2 vs. 2.1 months) without any additional toxicity (36). Most patients included in this retrospective analysis received multiple courses of salvage systemic therapies including irinotecan, lomustine, etoposide and bevacizumab prior to SRS. Another prospective trial found that a small cohort of patients tolerated concurrent bevacizumab with SRS (42). The impact of other systemic therapies is difficult to deduce as many included studies were retrospective in nature and the included patient population received multiple agents (36, 43-46).

\section{Prognostic indicators}

Cho et al. compared SRS and FSRT in recurrent HGG retrospectively and found that the two treatments yielded comparable survival. Although this was a non-randomized study, favorable prognostic factors included smaller tumor volume, younger age, high KPS and lower grade (47). Several other studies found age and performance status to be significantly associated with survival $(40,41,45)$. Two other retrospective reports showed that higher KPS and small tumor volume predicted for increased OS (48).

Time to recurrence may also play a role in predicting OS benefit. One retrospective study reported that longer interval between initial aggressive resection and recurrence correlated with survival (48). Similarly, Maranzano et al. described a potential survival benefit in patients that had adequate time ( $\geq 5$ months) between initial $\mathrm{RT}$ and $\mathrm{RT}$ at recurrence (38).

Patel et al. published a retrospective study stating survival was significantly improved in patients who either responded or had stable disease after SRS with median survival of 15.8 vs. 7.3 following radiosurgery (44). Interestingly, it has also been reported that patients treated after 2005 survive longer than those treated prior to this year. Sharma 
Table 2 FSRT in recurrent HGG

\begin{tabular}{|c|c|c|c|c|c|c|c|c|}
\hline First author & Year & $\begin{array}{l}\text { Number of } \\
\text { patients }\end{array}$ & $\begin{array}{l}\text { WHO } \\
\text { grade }\end{array}$ & $\begin{array}{c}\text { Dose and } \\
\text { fractionation }\end{array}$ & $\begin{array}{l}\text { Systemic } \\
\text { therapy }\end{array}$ & $\begin{array}{l}\text { MS from diagnosis } \\
\text { (months) }\end{array}$ & $\begin{array}{l}\text { MS from } \\
\text { FSRT (months) }\end{array}$ & $\begin{array}{c}\text { Grade } \geq 3 \\
\text { toxicity }\end{array}$ \\
\hline Hudes & 1997 & 20 & Grade III/IV & 24-35 Gy, 8-10 fx & None & - & 10.5 & $0 \%$ \\
\hline Cho (47) & 1999 & 25 & Grade III/IV & $\begin{array}{c}\text { 20-45 Gy, 10-20 fx, } \\
\text { median: 37.5 Gy }\end{array}$ & None & - & 12 & $30 \%$ \\
\hline Combs (49) & 2005 & 40 & Grade III & $\begin{array}{c}\text { 20-57.6 Gy, } 2 \text { Gy/fx, } \\
\text { median: } 36 \text { Gy }\end{array}$ & None & 48 & 16 & $0 \%$ \\
\hline Combs & 2005 & 172 & Grade II-IV & $\begin{array}{l}\text { 15-62 Gy, } 2 \text { Gy/fx, } \\
\text { median: } 36 \text { Gy }\end{array}$ & None & $\begin{array}{l}\text { 21/50/111; } \\
\text { Gr IV/III/II }\end{array}$ & $\begin{array}{l}\text { 8/16/22; } \\
\text { Gr IV/III/II }\end{array}$ & $0 \%$ \\
\hline Combs (50) & 2008 & 25 & Grade II-IV & $\begin{array}{c}\text { 25-45 Gy, } 2 \text { Gy/fx, } \\
\text { median: } 36 \text { Gy }\end{array}$ & TMZ & 59 & 8 & $0 \%$ \\
\hline Minniti & 2010 & 36 & Grade IV & 37.5 Gy, 15 fx & TMZ & 23.4 & 9.7 & $8 \%$ \\
\hline Fields & 2012 & 10 & Grade III/IV & 36 Gy, 3 fx & Vandetanib & 26.5 & 6 & $30 \%$ \\
\hline Clark (52) & 2014 & 21 & Grade III/IV & 30 Gy, 5 fx & $\begin{array}{l}\text { TMZ, CCNU, } \\
\text { Bevacizumab }\end{array}$ & - & 12.5 & $5 \%$ \\
\hline $\begin{array}{l}\text { Greenspoon } \\
\text { (53) }\end{array}$ & 2014 & 31 & Grade IV & 25-35 Gy, 5 fx & TMZ & - & 9 & $13 \%$ \\
\hline Wuthrick (54) & 2014 & 11 & Grade III/IV & 30-42 Gy, 10 fx & Sunitinib & - & 11 & $9 \%$ \\
\hline Shi & 2016 & 12 & Grade III/IV & 30-35 Gy, 10 fx & Panobinostat & - & $6.1-16.1$ & $58 \%$ \\
\hline
\end{tabular}

FSRT, fractionated stereotactic radiotherapy; HGG, high grade glioma; WHO, World Health Organization; MS, median survival; TMZ, temozolomide; Gy, Gray; fx, fraction.

et al. hypothesizes that this could be due to the treatment standardization of GBM patients after the publication of the Stupp protocol or that their institution started prescribing higher median prescription doses to smaller volumes around that time (46).

MGMT promoter methylation status is known to be a favorable prognostic factor in GBM patients. However, only a handful of the included studies documented MGMT status. One study showed a significant median OS benefit in patients with MGMT promoter methylation (33.4 vs. 16 months). However, only 22 patients had MGMT sequencing at the time of this study (41). Another report had 11 patients with MGMT promoter methylation, but did not find a statistically significant difference between OS in the cohort (40). A third study included 15 patients with MGMT sequencing results and only 5 with MGMT promoter methylation. Survival statistics were not provided on this subgroup (46).

Imber et al. reported a trend toward decreased OS in patients in which multiple targets were treated with SRS $(37,38)$. Twenty-one percent of patients in one study had multiple lesions upon recurrence. It is unclear how many of those recurrent lesions were treated with SRS, but their survival was similar to the other studies included in this review. Pinzi et al. did not find any significant OS difference between patients with multiple treated lesions $v s$. a single lesion (45).

\section{FSRT}

There have been a variety of dose and fractionation regimens used for FSRT treatment in the setting of 
recurrent high-grade glioma, as detailed in Table 2. In a study comparing the efficacy of SRS versus FSRT in recurrent WHO Grade III and Grade IV tumors, Cho et al. used a median dose of 37.5 Gy in 15 fractions for their FSRT arm (47). Similarly, Minniti et al. evaluated the efficacy of salvage FSRT in combination with TMZ with a dose of 37.5 Gy in 15 fractions (56). Both of these studies represent modestly hypofractionated radiation regimens with 2.5 Gy per fraction. In contrast, a Phase I doseescalation study investigating FSRT given in combination with gefitinib for recurrent HGG, Schwer et al. were able to deliver 36 Gy in 3 fractions without doselimiting toxicity (31). In addition, Fields et al. gave $36 \mathrm{~Gy}$ in 3 fractions of FSRT in combination with dose-escalated vandetanib in their phase I trial for recurrent malignant glioma. These two trials represent the most aggressively hypofractionated FSRT regimens, with biologically effective dose approaching that of SRS regimens (32). The median dose of the literature surveyed in this review as shown in Table 2 is approximately 35 Gy in 10 fractions, although many trials did allow for dose variation to account for prior radiation dose, proximity to critical structures, and size of the recurrent lesion.

Toxicity remains a concern with FSRT treatment for recurrent high-grade glioma, although perhaps to a lesser degree as compared to SRS, given the normal tissue repair capacity between fractions of radiation. Many of the FSRT studies referenced in Table 2 quoted a zero percent rate of Grade III or higher toxicity. Hudes et al.'s paper aimed to determine the optimal dose of FSRT while decreasing rates of re-operation due to SRS toxicity (30). Shi et al.'s 2018 retrospective review of recurrent HGG patients who progressed on bevacizumab and subsequently received FSRT also noted no treatment-related Grade III or higher toxicity (57). In contrast, a Phase I study investigating the role of combining panobinostat and FSRT reported a $58 \%$ rate of Grade III or higher toxicity, although much of this was hematologic and associated with the oral radiosensitizing agent, with only one Grade III RN event (58). In direct comparison studies, such as Cho et al., of FSRT versus SRS-where the confounder of concurrent systemic therapy was not present-toxicity rates as a whole, and particularly radiation necrosis rates, are significantly lower when using FSRT (47).

\section{Conclusion}

Both SRS and FSRT have shown efficacy and safety in a variety of different dose and fractionation schedules in recurrent HGG. Further conclusions are difficult to delineate as the included studies used varying inclusion criteria, doses, and systemic therapies (concurrent or adjuvant). It is important to note that the majority of the included studies did not comment on MGMT status which is known to impact survival. Most studies included in this review reported toxicity of therapeutic intervention, but few recorded quality of life and neurocognitive changes. Further prospective trials are ongoing and necessary to further elucidate a standard of care for these patients.

\section{Acknowledgments}

Funding: None.

\section{Footnote}

Conflicts of Interest: All authors have completed the ICMJE uniform disclosure form (available at http://dx.doi. org/10.21037/cco.2020.03.05). WS: Consulting for Novocure, Brainlab, and Varian. Research funding from Regeneron, Brainlab, Novocure. The other authors have no conflicts of interest to declare.

Ethical Statement: The authors are accountable for all aspects of the work in ensuring that questions related to the accuracy or integrity of any part of the work are appropriately investigated and resolved.

Open Access Statement: This is an Open Access article distributed in accordance with the Creative Commons Attribution-NonCommercial-NoDerivs 4.0 International License (CC BY-NC-ND 4.0), which permits the noncommercial replication and distribution of the article with the strict proviso that no changes or edits are made and the original work is properly cited (including links to both the formal publication through the relevant DOI and the license). See: https://creativecommons.org/licenses/by-nc-nd/4.0/.

\section{References}

1. American Cancer Society. Cancer Facts \& Figures 2019. Atlanta: American Cancer Society; 2019.

2. Diwanji TP, Engelman A, Snider JW, et al. Epidemiology, diagnosis, and optimal management of glioma in adolescents and young adults. Adolesc Health Med Ther 2017;8:99. 
3. Ostrom QT, Gittleman H, Fulop J, et al. CBTRUS statistical report: primary brain and central nervous system tumors diagnosed in the United States in 2008-2012. Neuro Oncol 2015;17:iv1-62.

4. Stupp R, Mason WP, Van Den Bent MJ, et al. Radiotherapy plus concomitant and adjuvant temozolomide for glioblastoma. N Engl J Med 2005;352:987-96.

5. Stupp R, Hegi ME, Mason WP, et al. Effects of radiotherapy with concomitant and adjuvant temozolomide versus radiotherapy alone on survival in glioblastoma in a randomised phase III study: 5-year analysis of the EORTC-NCIC trial. Lancet Oncol 2009;10:459-66.

6. Cairncross G, Wang M, Shaw E, et al. Phase III trial of chemoradiotherapy for anaplastic oligodendroglioma: long-term results of RTOG 9402. J Clin Oncol 2013;31:337.

7. Stupp R, Wong ET, Kanner AA, et al. NovoTTF-100A versus physician's choice chemotherapy in recurrent glioblastoma: a randomised phase III trial of a novel treatment modality. Eur J Cancer 2012;48:2192-202.

8. Lacroix M, Abi-Said D, Fourney DR, et al. A multivariate analysis of 416 patients with glioblastoma multiforme: prognosis, extent of resection, and survival. J Neurosurg 2001;95:190-8.

9. Gilbert MR, Dignam JJ, Armstrong TS, et al. A randomized trial of bevacizumab for newly diagnosed glioblastoma. N Engl J Med 2014;370:699-708.

10. van den Bent MJ, Baumert B, Erridge SC, et al. Interim results from the CATNON trial (EORTC study 2605322054) of treatment with concurrent and adjuvant temozolomide for $1 \mathrm{p} / 19 \mathrm{q}$ non-co-deleted anaplastic glioma: a phase 3, randomised, open-label intergroup study. Lancet 2017;390:1645-53.

11. Laub CK, Stefanik J, Doherty L. Approved treatments for patients with recurrent high-grade gliomas. Semin Oncol Nurs 2018;34:486-93.

12. Weller M, Cloughesy T, Perry JR, et al. Standards of care for treatment of recurrent glioblastoma are we there yet? Neuro Oncol 2013;15:4-27.

13. Shi W, Bryan MS, Gilbert MR, et al. Investigating the effect of reirradiation or systemic therapy in patients with glioblastoma after tumor progression: a secondary analysis of NRG oncology/radiation therapy oncology group trial 0525. Int J Radiat Oncol Biol Phys 2018;100:38-44.

14. Fogh SE, Andrews DW, Glass J, et al. Hypofractionated stereotactic radiation therapy: an effective therapy for recurrent high-grade gliomas. J Clin Oncol 2010;28:3048.

15. Halperin EC, Brady LW, Pérez CA. Perez and Bradys principles and practice of radiation oncology. Philadelphia: Wolters Kluwer; 2019.

16. Combs SE, Debus J, Schulz-Ertner D. Radiotherapeutic alternatives for previously irradiated recurrent gliomas. Bmc Cancer 2007;7:167.

17. Chin LS, Regine WF. Principles and practice of stereotactic radiosurgery. Springer Science \& Business Media; 2010.

18. Brady LW, Perez CA, Wazer DE. Perez \& Brady's principles and practice of radiation oncology. Lippincott Williams \& Wilkins; 2013.

19. Kirkpatrick JP, Soltys SG, Lo SS, et al. The radiosurgery fractionation quandary: single fraction or hypofractionation?. Neuro Oncol 2017;19:ii38-49.

20. Fetcko K, Lukas RV, Watson GA, et al. Survival and complications of stereotactic radiosurgery: A systematic review of stereotactic radiosurgery for newly diagnosed and recurrent high-grade gliomas. Medicine (Baltimore) 2017;96:e8293.

21. Elaimy AL, Mackay AR, Lamoreaux WT, et al. Clinical outcomes of gamma knife radiosurgery in the salvage treatment of patients with recurrent high-grade glioma. World Neurosurg 2013;80:872-8.

22. Niranjan A, Kano H, Iyer A, et al. Role of adjuvant or salvage radiosurgery in the management of unresected residual or progressive glioblastoma multiforme in the pre-bevacizumab era. J Neurosurg 2015;122:757-65.

23. Conti A, Pontoriero A, Arpa D, et al. Efficacy and toxicity of CyberKnife re-irradiation and "dose dense" temozolomide for recurrent gliomas. Acta Neurochirurgica 2012;154:203-9.

24. Skeie BS, Enger PØ, Brøgger J, et al. Gamma knife surgery versus reoperation for recurrent glioblastoma multiforme. World Neurosurg 2012;78:658-69.

25. Martínez-Carrillo M, Tovar-Martín I, Zurita-Herrera $M$, et al. Salvage radiosurgery for selected patients with recurrent malignant gliomas. Biomed Res Int 2014;2014:657953.

26. Koga T, Maruyama K, Tanaka M, et al. Extended field stereotactic radiosurgery for recurrent glioblastoma. Cancer 2012;118:4193-200.

27. Ene CI, Macomber MW, Barber JK, et al. Patterns of Failure After Stereotactic Radiosurgery for Recurrent High-Grade Glioma: A Single Institution Experience of 10 Years. Neurosurgery 2019;85:E322-31.

28. Wallner KE, Galicich JH, Krol G, et al. Patterns of failure following treatment for glioblastoma multiforme and anaplastic astrocytoma. Int J Radiat Oncol Biol Phys 
1989;16:1405-9.

29. Shaw E, Scott C, Souhami L, et al. Single dose radiosurgical treatment of recurrent previously irradiated primary brain tumors and brain metastases: final report of RTOG protocol 90-05. Int J Radiat Oncol Biol Phys 2000;47:291-8.

30. Hudes RS, Corn BW, Werner-Wasik M, et al. A phase I dose escalation study of hypofractionated stereotactic radiotherapy as salvage therapy for persistent or recurrent malignant glioma. Int J Radiat Oncol Biol Phys 1999;43:293-8.

31. Schwer AL, Damek DM, Kavanagh BD, et al. A phase I dose-escalation study of fractionated stereotactic radiosurgery in combination with gefitinib in patients with recurrent malignant gliomas. Int J Radiat Oncol Biol Phys 2008;70:993-1001.

32. Fields EC, Damek D, Gaspar LE, et al. Phase I dose escalation trial of vandetanib with fractionated radiosurgery in patients with recurrent malignant gliomas. Int J Radiat Oncol Biol Phys 2012;82:51-7.

33. Emami B, Lyman J, Brown A, et al. Tolerance of normal tissue to therapeutic irradiation. Int J Radiat Oncol Biol Phys 1991;21:109-22.

34. Mayer R, Sminia P. Reirradiation tolerance of the human brain. Int J Radiat Oncol Biol Phys 2008;70:1350-60.

35. Sminia P, Mayer R. External beam radiotherapy of recurrent glioma: radiation tolerance of the human brain. Cancers 2012;4:379-99.

36. Cuneo KC, Vredenburgh JJ, Sampson JH, et al. Safety and efficacy of stereotactic radiosurgery and adjuvant bevacizumab in patients with recurrent malignant gliomas. Int J Radiat Oncol Biol Phys 2012;82:2018-24.

37. Imber BS, Kanungo I, Braunstein S, et al. Indications and efficacy of gamma knife stereotactic radiosurgery for recurrent glioblastoma: 2 decades of institutional experience. Neurosurgery 2017;80:129-39.

38. Maranzano E, Anselmo P, Casale M, et al. Treatment of recurrent glioblastoma with stereotactic radiotherapy: long-term results of a mono-institutional trial. Tumori 2011;97:56-61.

39. Kong DS, Lee JI, Park K, et al. Efficacy of stereotactic radiosurgery as a salvage treatment for recurrent malignant gliomas. Cancer 2008;112:2046-51.

40. Sutera PA, Bernard ME, Gill BS, et al. Salvage stereotactic radiosurgery for recurrent gliomas with prior radiation therapy. Future Oncol 2017;13:2681-90.

41. Frischer JM, Marosi C, Woehrer A, et al. Gamma knife radiosurgery in recurrent glioblastoma. Stereotact Funct
Neurosurg 2016;94:265-72.

42. Cabrera AR, Cuneo KC, Desjardins A, et al. Concurrent stereotactic radiosurgery and bevacizumab in recurrent malignant gliomas: a prospective trial. Int J Radiat Oncol Biol Phys 2013;86:873-9.

43. Bokstein F, Blumenthal DT, Corn BW, et al. Stereotactic radiosurgery (SRS) in high-grade glioma: judicious selection of small target volumes improves results. J Neurooncol 2016;126:551-7.

44. Patel M, Siddiqui F, Jin JY, et al. Salvage reirradiation for recurrent glioblastoma with radiosurgery: radiographic response and improved survival. J Neurooncol 2009;92:185.

45. Pinzi V, Orsi C, Marchetti M, et al. Radiosurgery reirradiation for high-grade glioma recurrence: a retrospective analysis. Neurol Sci 2015;36:1431-40.

46. Sharma M, Schroeder JL, Elson P, et al. Outcomes and prognostic stratification of patients with recurrent glioblastoma treated with salvage stereotactic radiosurgery. J Neurosurg 2018;131:489-99.

47. Cho KH, Hall WA, Gerbi BJ, et al. Single dose versus fractionated stereotactic radiotherapy for recurrent high-grade gliomas. Int J Radiat Oncol Biol Phys 1999;45:1133-41.

48. Elliott RE, Parker EC, Rush SC et al. Efficacy of gamma knife radiosurgery for small-volume recurrent malignant gliomas after initial radical resection. World Neurosurg 2011;76:128-40.

49. Combs SE, Gutwein S, Thilmann C, et al. Reirradiation of recurrent WHO grade III astrocytomas using fractionated stereotactic radiotherapy (FSRT). Strahlenther Onkol 2005;181:768-73.

50. Combs SE, Bischof M, Welzel T, et al. Radiochemotherapy with temozolomide as re-irradiation using high precision fractionated stereotactic radiotherapy (FSRT) in patients with recurrent gliomas. J Neurooncol 2008;89:205-10.

51. Gutin PH, Iwamoto FM, Beal K, et al. Safety and efficacy of bevacizumab with hypofractionated stereotactic irradiation for recurrent malignant gliomas. IInt J Radiat Oncol Biol Phys 2009;75:156-63.

52. Clark GM, McDonald AM, Nabors L, et al. Hypofractionated stereotactic radiosurgery with concurrent bevacizumab for recurrent malignant gliomas: the University of Alabama at Birmingham experience. Neurooncol Pract 2014;1:172-7.

53. Greenspoon JN, Sharieff W, Hirte H, et al. Fractionated stereotactic radiosurgery with concurrent temozolomide chemotherapy for locally recurrent glioblastoma 
multiforme: a prospective cohort study. Onco Targets Ther 2014;7:485.

54. Wuthrick EJ, Curran Jr WJ, Camphausen K, et al. A pilot study of hypofractionated stereotactic radiation therapy and sunitinib in previously irradiated patients with recurrent high-grade glioma. Int J Radiat Oncol Biol Phys 2014;90:369-75.

55. Song A, Andrews DW, Werner-Wasik M, et al. Phase I trial of alisertib with concurrent fractionated stereotactic re-irradiation for recurrent high grade gliomas. Radiother Oncol 2019;132:135-41.

56. Minniti G, Armosini V, Salvati M, et al. Fractionated

Cite this article as: Ali AS, Chen VE, Zurlo C, Taylor JM, Fernandez C, Shi W. Target treatment with stereotactic radiation for recurrent gliomas. Chin Clin Oncol 2020;9(6):74. doi: $10.21037 /$ cco.2020.03.05 stereotactic reirradiation and concurrent temozolomide in patients with recurrent glioblastoma. J Neurooncol 2011;103:683-91.

57. Shi W, Blomain ES, Siglin J, et al. Salvage fractionated stereotactic re-irradiation (FSRT) for patients with recurrent high grade gliomas progressed after bevacizumab treatment. J Neurooncol 2018;137:171-7.

58. Shi W, Palmer JD, Werner-Wasik M, et al. Phase I trial of panobinostat and fractionated stereotactic re-irradiation therapy for recurrent high grade gliomas. J Neurooncol 2016;127:535-9. 